\title{
STRATEGI PEMASARAN MANGGA GEDONG GINCU KABUPATEN SUMEDANG
}

\section{MARKETING STRATEGY LEVEL OF GEDONG GINCU MANGGA, SUMEDANG REGENCY}

\author{
KOSASIH SUMANTRI*, IDA MARINA, DINAR, ENI KURNIATI \\ Program Studi Agribisnis Fakultas Pertanian Universitas Majalengka \\ Jl. Raya K H Abdul Halim No. 103, Majalenka Kulon, Kec. Majalengka, Kab. \\ Majalengka, Jawa Barat 45418 \\ e-mail : kosasihsumantri@unma.ac.id
}

\begin{abstract}
The demand for mangoes in the market continues to increase, both fresh and processed mangoes, but this is not accompanied by marketing commitments. This research was conducted in Palabuan Village, Ujungjaya District, Sumedang Regency which aims to find out the strategies applied in developing the mango gedong gincu business. The research was conducted on a mango business in Palabuan Village which is the only place to collect gedong gincu mangoes in Ujungjaya District. The method used is through interviews and observations. The data obtained then uses SWOT and QSPM analysis. Respondents in this study amounted to 5 people. The mango gedong gincu business strategy that can be applied includes: WO strategy in which there are points: adding new workers to fulfill market demand, using packaging that is more attractive to consumers, creating special strategies in attracting consumers to further increase sales and increase the number production, conduct promotions for newly explored markets, with the hope of increasing the number of customer.
\end{abstract}

Keyword : Mango Gedong Gincu, Marketing Strategy, Demand.

\begin{abstract}
ABSTRAK
Permintaan akan mangga di pasar terus meningkat baik mangga buah segar maupun yang sudah diolah, namun tidak dibareungi dengan pengitan pemasaran. Penelitian ini dilakukani di Desa Palabuan Kecamatan Ujungjaya Kabupaten Sumedang yang bertujuan mengetahui mengetahui strategi yang diterapkan dalam pengembangan usaha mangga gedong gincu. Penelitian dilakukan pada usaha mangga di Desa Palabuan yang menjadi satu-satunya tempat pengumpul mangga gedong gincu di Kecamatan Ujungjaya. Metode yang digunakan melalui wawancara dan observasi.. Data yang diperoleh selanjutnya menggunakan analisis SWOT dan QSPM. Responden pada penelitian ini berjumlah 5 orang. Strategi usaha mangga gedong gincu yang dapat diterapkan anatara lain : Strategi W-O yang didalamnya terdapat poin-poin: menambah tenaga kerja baru agar terpenuhinya permintaan pasar, menggunakan kemasan yang lebih menarik minat konsumen, menciptakan strategi khusus dalam menarik konsumen agar lebih meningkatkan penjualan dan menambah jumlah produksi, mengadakan promosi bagi pasar-pasar yang baru dijajaki, dengan harapan menambah jumlah pelanggan.
\end{abstract}

Kata kunci : Mangga Gedong Gincu, Strategi Pemasaran, Permintaan

\section{PENDAHULUAN \\ Latar Belakang}

Permintaan akan mangga di pasar terus meningkat baik mangga buah segar maupun yang sudah diolah. Mangga juga jenis buah tropis yang digemari masyarakat di dunia dan menjadi komoditas perdagangan antar negara komoditas hortikultura, khususnya buah-buahan salah satunya buah mangga mempunyai prospek baik bila di kembangkan secara intensif dan dalam skala argbisnis dari tahun ke tahun permintaan buah tropis di dalam dan di luar negeri semakin meningkat. Adanya prospek yang baik bagi pengembangan agribisnis mangga, maka mangga sebagai komoditi hortikultura unggulan sudah seharusnya di kembangkan secara intensif dalam skala agribisnis, 
terutama mangga sebagai kegiatan usaha tani kerakyatan yang mendukung peningkatan pendapatan masyarakat.

Komoditas mangga sebagai salah satu sumber pertumbuhan pembangunan hortikultura, sasaran pengembangan budidaya dalam skala agribisnis dan agroindustri, selain untuk meningkatkan produksi, juga diharapkan dapat mendorong perluasan kesempatan berusaha dan lapang kerja, menunjang pengembangan industri pengolahan dan meningkatan pendapatan petani, menekan impor dan memacu pertumbuhan ekspor. Usaha agribisnis mangga dengan berorientasi pasar ditujukan untuk membangun keunggulan kompetitif berdasarkan keunggulan komparatif wilayah. Komoditas mangga mempunyai potensi dan peluang yang cukup besar untuk bersaing dalam perdagangan global.

Peluang pasar ekspor mangga gedong gincu cukup besar dikarenakan buahnya mempunyai kelebihan dibandingkan jenis mangga lainnya yaitu dapat di panen dua bentuk, pertama bentuk gedong (tingkat kematangan 60\%) dan gedong gincu (tingkatan kematangan 70\%), dengan perbedaan waktu panen antara 10 sampai 15 hari. Gedong gincu akhir-akhir ini mempunyai peluang pasar cukup besar baik pasar domestic maupun pasar ekspor karena buahnya mempunyai aroma sangat tajam, warna buah merah menyala dan mengandung banyak serat. Karakteristik ini sangat sesuai dengan permintaan negara importer (Yuliawati,2020).

Mangga Gedong Gincu dengan nama lain mangga Gedong mengeluarkan warna kuning atau jingga pada kulit buah karena matang pohon. Mangga Gedong Gincu memiliki ciri khas sebagai buah mangga yang eksotik karena warna merah semburat dekat pangkal tangkai, rasanya manis keasaman serat daging buahnya halus berserat dan beraroma harum (Asfi,2016). Keunggulan tersebut menjadikan Mangga Gedong Gincu memiliki harga jual yang cukup tinggi. Pada tingkat konsumen domestik saat panen kecil harga jualnya mencapai Rp25.000.00Rp60.000.00 per kg. Terdapat 13 varietas mangga yang di hasilkan Kabupaten Sumedang, salah satunya Mangga Gedong gincu dan Cengkir yang paling di gemari dan banyak dicari konsumen (BPTBT 2015). Kabupaten sumedang merupakan daerah yang sesuai untuk budidaya mangga karena wilayahnya berupa dataran landai dan jumlah hari hujan rata-rata 75 hari sehingga menunjang hasil produksi buah mangga menjadi lebih baik (Pemerintak Kabupaten Sumedang, 2020).

Dulihat dari aspek konsumen manga gedong gincu berdasarkan karakteristik terbagi kedalam karakteristik individu dan produk. Ditinjau dari segi karakteristik individu mayoritas konsumen selalu mengaitkan keadaan pribadi/individu sebelum mengambil keputusan pembelian, seperti motivasi, persepsi, keluarga, wilayah tempat tinggal dan pendapatan. Sedangkan dari segi karakteristik produk mayoritas konsumen menginginkan rasa yang manis, warna kuning/kuning semburat merah, tekstur yang kenyal dan lembut, aroma yang khas dan harga yang tidak terlalu tinggi (Yuliawati, 2020).

Kabupaten sumedang merupakan daerah yang sesuai untuk budidaya mangga karena wilayahnya berupa dataran landai dan jumlah hari hujan rata-rata 75 hari sehingga menunjang hasil produksi buah mangga menjadi lebih baik. Perkembangan produksi mangga di Kabupaten Sumedang pada tahun 2016 sampai taun 2020 mengalami fluktuasi produksi yang cukup signifikan seperti yang dapat dilihat pada Gambar 1.

Pada tahun 2020 produksi mangga di Sumedang mencapai 31.867 ton. Jumlah tersebut menunjukkan adanya kenaikan produksi mangga di Kabupaten Sumedang sebesar 44 persen dibandingkan dengan produksi pada tahun 2010 yaitu sebesar 34 903.04 ton. Perkembangan produksi mangga gedong gincu di kabupaten sumedang merupakan salah satu sentra komoditas mangga gedong gincu di wilayah jawa barat. Berdasarkan laporan dari dinas pertanian, mangga gedong gincu di kabupaten sumedang memiliki luas tanam pada tahun 2019 seluas 3.410 ha dan produktivitas sebesar 74 ton. 


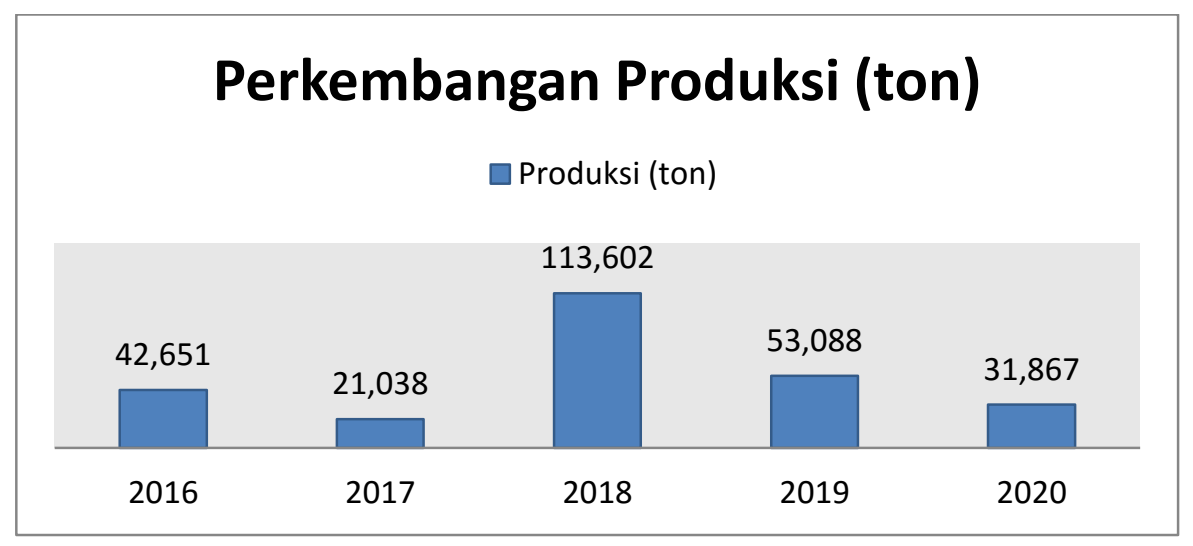

Gambar 1 Perkembangan produksi (ton) di Kabupaten Sumedang tahun 2016-2020

Sumber : Dinas Pertanian Kabupaten Sumedang (2020).

Tingginya potensi Kabupaten Sumedang sebagai salah satu sentra mangga gedong gincu di Jawa Barat, ternyata di dalamnya masih menyisikan beberapa masalah. Salah satunya yaitu permasalahan dalam pemasaran yang di dalamnya melibatkan berbagai lembaga pemasaran. Permasalah yang sering muncul dalam sistem agribisnis hortikultura pada umumnya adalah permasalahan mulai dari tahapan produksi hingga tahapan pemasaran hasil hasil. Hortikultura belum sepenuhnya memberikan insentif yang optimal kepada petani yang selama ini mengusahakan. Maka dari itu dengan segala permasalahan dalam agribisnis hortikultura dalam hal ini manga gedong gincu, yang menjadi tujuan dari pelaksanaan penelitian ini adalah untuk mengetahui strategi yang diterapkan dalam pengembangan usaha mangga gedong gincu.

\section{MATERI DAN METODE}

Penelitian ini dilakukan di Desa Palabuan Kecamatan Ujungjaya Kabupaten Sumedang Provinsi Jawa Barat. Waktu penelitian dimulai bulan Juni sampai dengan bulan Agustus 2021. Metode yang digunakan dalam penelitian ini adalah metode Deskriptif Kualitatif. Jenis dan sumber data yang digunakan dalam penelitian ini adalah data primer dan sekunder. Cara pengumpulan data menggunakan kusioner, wawancara, studi Pustaka dan observasi. Penentuan responden dilakukan dengan teknik survei yang diperoleh dari data petani mangga yang berada di Desa Palabuan Kecamatan Ujungjaya Kabupaten Sumedang dengan jumlah 5 orang. Data yang diambil dapat berasal dari hasil wawancara, obesrvasi dan pencatatan. Analisis ini didasarkan pada usaha untuk memaksimalkan kekuatan dan peluang, namun dapat meminimalkan kelemahan dan ancaman secara bersama (Marina,I.dkk. 2017).

\section{HASIL DAN PEMBAHASAN}

\section{Kondisi Pemasaran}

Pemasaran di tempat penelitian memulai bisnis mangga gedong gincu dengan sasaran utama adalah pasar induk. Pasar induk yang menjadi tujuan adalah pasar Jakarta, pasar bandung.

Penentuan positioning produk ppada kasus ini diharapkan dapat menciptakan image produk yang dihasilkan di benak konsumen. Dimana memposisikan mangga Gedong Gincunya sebagai produk mangga Gedong Gincu yang eksotis dan berkualitas.

Di tempat penelitian mangga gedong gincu segar yang dijual berasal dari kebun sendiri atau kebun para petani sekitar yang melakukan kerjasama atau petani sekitar tempat penelitian yang menjual manga yang mereka usahakan

Harga mangga Gedong Gincu yang dijual tergantung pada musim panen. Ketika panen kecil, kuantitas mangga Gedong Gincu yang dihasilkan tidak sebanyak pada saat panen raya. Pada saat panen kecil, mampu mengirim 12 ton mangga Gedong Gincu grade I per bulan kepada pasar tradisonal sedangkan pada saat panen raya, mampu 
mengirim 20 ton mangga Gedong Gincu grade I.

$$
\text { Kegiatan pemasaran suatu }
$$
perusahaan sangat berkaitan dengan cara menyampaikan (mendistribusikan) produk yang dihasilkan hingga sampai kepada konsumen. Pengiriman mangga dilakukan ketika sore atau malam hari. Kendaraan yang digunakan untuk mengirim mangga Gedong Gincu adalah mobil bak terbuka yang ditutupi oleh terpal.

\section{Indentifikasi Faktor Internal dan Eksternal}

Matriks SWOT digunakan untuk merumuskan alternatif strategi pemasaran yang dapat diterapkan pada usaha mangga gedong gincu. Matriks SWOT dapat menggambarkan secara jelas bagaimana peluang dan ancaman eksternal yang dihadapi oleh usaha tersebut dapat disesuaikan dengan kekuatan dan kelemahan internal. Matrik ini menghasilakn empat sel kemungkinan alternatif strategi, yaitu strategi S-O, strategi W-O, strategi W-T dan strategi S-T.

Tabel 1. Faktor-faktor Internal Usaha Mangga Gedong Gincu di Desa Palabuan

\begin{tabular}{|c|c|c|c|c|c|c|}
\hline \multicolumn{2}{|c|}{ Faktor Internal } & \multicolumn{2}{|c|}{ Bobot } & \multicolumn{2}{|c|}{ Rating } & \multirow{2}{*}{$\begin{array}{l}\text { Bobot } \\
\text { Rating }\end{array}$} \\
\hline & \multicolumn{5}{|l|}{ Kekuatan } & \\
\hline 1. & Pengalaman berusaha & 0,12 & & 3 & & 0,36 \\
\hline 2. & $\begin{array}{l}\text { kemampuan yang cukup } \\
\text { professional }\end{array}$ & & 3 & & 0,33 & \\
\hline 3. & $\begin{array}{l}\text { Mangga yang dihasilkan cukup } 0,11 \\
\text { Berkualitas }\end{array}$ & & 3 & & 0,33 & \\
\hline 4. & $\begin{array}{l}\text { Konsumen merasa mangga cukup } \\
\text { Berkualitas }\end{array}$ & 0,10 & & 3 & & 0,33 \\
\hline 5. & $\begin{array}{l}\text { Adanya kerjasama dengan petani } \\
\text { Lain }\end{array}$ & 0,10 & & 3 & & 0,33 \\
\hline 6. & Saluran pemasaran pendek & 0,09 & & 3 & & 0,27 \\
\hline \multirow[t]{2}{*}{7.} & $\begin{array}{l}\text { Harga yang ditawarkan kepada } 0,10 \\
\text { Pembeli sesuai yang ditawarkan }\end{array}$ & & 3 & & 0,33 & \\
\hline & Kelemahan & & & & & \\
\hline 1. & Alat yang digunakan tidak lengkap & 0,07 & & 2 & & 0,14 \\
\hline 2. & Kemasan yang kurang menarik 0,07 & & 2 & & 0,14 & \\
\hline 3. & $\begin{array}{l}\text { Tidak ada strategi khusus dalam } 0,07 \\
\text { Menarik konsumen }\end{array}$ & & 2 & & 0,14 & \\
\hline 4. & Tidak adanya promosi & 0,04 & & 1 & & 0,04 \\
\hline
\end{tabular}

Matriks SWOT diatas menghasilkan alternatif strategis sebagai berikut :

a. Strategi S-O: Menghasilkan mangga yang berkualitas dan menambah jumlah produksi, menjajaki daerah pemasaran baru yang memiliki potensi terhadap peningkatan penjualan mangga dengan menggunakan saluran pemasaran yang pendek, meningkatkan kerjasama dengan petani lain agar terpenuhinya permintaan pasar. b. Strategi S-T: memberikan pelayanan terbaik kepada konsumen agar konsumen percaya dan loyal terhadap mangga yang kita jual.

c. Strategi W-O: Menambahkan tenaga kerja baru agar terpenuhinya permintaan pasar, menggunakan kemasan yang lebih menarik untuk menarik minat konsumen, menciptakan strategi khusus dalam menarik minat konsumen, menciptakan strategi khusus dalam menarik konsumen agar lebih 
meningkatkan penjual dan menambah jumlah produksi, mengadakan promosi bagi pasar-pasar yang baru dijajaki, agar menambah jumlah pelanggan. d. Strategi W-T: Menambah jumlah produksi agar selalu terpenuhinya keebutuhan pasar.

Tabel 2. Faktor-faktor Eksternal Usaha Mangga Gedong Gincu di Desa Palabuan

\begin{tabular}{|c|c|c|c|c|c|}
\hline \multicolumn{3}{|c|}{ Faktor Eksternal } & \multirow[t]{2}{*}{ Bobot } & \multirow[t]{2}{*}{ Rating } & \multirow{2}{*}{$\begin{array}{l}\text { Bobot } \\
\text { Rating }\end{array}$} \\
\hline \multirow{2}{*}{\multicolumn{6}{|c|}{ Peluang }} \\
\hline & & & & & \\
\hline 1. & Banyaknya pelanggan & & 0,333 & 3 & 0,999 \\
\hline 2. & $\begin{array}{l}\text { Mangga berproduksi } \\
\text { Setiap musim }\end{array}$ & & 0,296 & 3 & 0,888 \\
\hline \multicolumn{6}{|c|}{ Ancaman } \\
\hline 1. & Tidak mempunyai pemasokan & 0,166 & & & \\
\hline 2. & Banyaknya pesaing & & 0,092 & 1 & 0,092 \\
\hline 3. & Dukungan dari pemerintah & & 0,111 & 1 & 0,111 \\
\hline
\end{tabular}

Hasil analisis Matrik Internal dan Matriks SWOT, diperoleh alternative strategi yang akan diterapkan bagi pengusaha mangga, untuk menghasilkan prioritas strategi yang paling tepat dan utama bagi pengusaha mangga, maka dilakukan analisis menggunakan Matrik QSP untuk pengambilan keputusan. Matrik QSP memberikan kelebihan-kelebihan dari masing-masing strategi, yang selanjutnya memberi dasar obyektif untuk dapat memilih salah satu atau beberapa strategi sfesifik yang menjadi pilihan. . Prioritas alternatif strategi usaha mangga gedong gincu yang dapat diterapkan anataralain : Strategi W-O yang didalamnya terdapat poin-poin: menambah tenaga kerja baru agar terpenuhinya permintaan pasar, menggunakan kemasan yang lebih menarik minat konsumen, menciptakan strategi khusus dalam menarik konsumen agar lebih meningkatkan penjualan dan menambah jumlah produksi, mengadakan promosi bagi pasar-pasar yang baru dijajaki, dengan harapan menambah jumlah pelanggan.

\section{Kesimpulan}

Berdasarkan hasil penelitian dapat disimpulkan yaitu Mangga Gedong Gincu segar di tempat penelitian berasal dari kebun sendiri dan dari kebun petani lainnya. Mangga gedong gincu yang di produksi terdiri dari dua kategori yaitu kategori grade I dan grade II. Harga mangga gedong gincu yang dijual bergantung pada musim panen berkisar antara Rp. 15.000 - Rp. 25.000 per $\mathrm{kg}$. Ketika panen kecil, kualitas mangga gedong gincu yang dihasilkan tidak sebanyak pada saat panen raya dengat tujuan pemasaran pasar induk Bandung dan Jakarta. strategi usaha mangga gedong gincu yang dapat diterapkan anataralain : Strategi W-O dalam memenuhi permintaan pasar melalui penambahan tenaga kerja, pengemasan yang lebih menarik, mengadakan promosi bagi pasar-pasar yang baru dijajaki, dengan harapan menambah jumlah pelanggan

\section{DAFTAR PUSTAKA}

ASFI, M., F. WICAKSONO, KUSNADI DAN P. SUKIBI. 2016. Sistem Informasi Geografis Pemetaan Spesifikasi Mangga Gedong Gincu di Wilayah III Cirebon. http://teknik.untagcirebon.ac.id/publi kasi/index.php/snirt/article/view/18/4 Diakses 27 Februari 2018.

BALAI PENELITIAN TANAMAN BUAH TROPIKA (BPTBT), 2015. Mangga Gedong Gincu dan Kesehatan. https://balitbu.litbang.pertanian.go.id /images/leaflet/gedonggincu.pdf

DINAS PERTANIAN KAB. SUMEDANG, 2020. Perkembangan Produksi (ton) di Kabupaten sumedang 2016-2020. 
PEMERINTAH

KABUPATEN

SUMEDANG, 2020. Demografi dan

Topografi Kab. Sumedang.

https://sumedangkab.go.id/profil

KEMENTERIAN PERTANIAN. 2012. Deskripsi Varietas Jagung Unggul. Edisi Ke-7. Pusat Penelitian dan Pengembangan Tanaman Pangan. Jakarta. $134 \mathrm{hlm}$.

KS, YULIAWATI, MARINA,I. 2020.

Analisis Preferensi Konsumen

Terhadap Keputusan Pembelian

Buah Mangga Gedong Gincu

(Mangifera indica L).

https://scholar.google.com/citations?

view_op=view_citation\&hl=id\&user

$=5 \mathrm{KL} \_$HKOAAAAJ\&citation_for_vi

ew $=5 \mathrm{KL} \_$HK0AAAAJ:5nxA0vEk-

isC

MARINA,I. dkk. 2017. Strategi Pengembangan Agribisnis Hasil Pertanian Melalui Inovasi Dan Kreatifitas Menjadi Produk Unggulan Di Smk Negeri 1 Pacet Kabupaten Cianjur. https://jurnal.unigal.ac.id/index.php/ mimbaragribisnis/article/viewFile/31 127

Nilasari A. N., JB. S. Heddy dan T. Wardiyati. 2013. Identifikasi keragaman morfologi daun mangga (Mangifera indica L.) pada tanaman hasil persilangan antara varietas arumanis 143 dengan podang urang umur 2 tahun. Jurnal Produksi Tanaman Volume 1 No.1.

Rangkut, Freedy, Analisis SWOT (Jakarta: PT Gramedia Pustaka Utama, 2014)hal 6

Supriatna, Ade. 2005. Budidaya dan Prospek Pemasaran Mangga Gedong Gincu Sinar Tani. Kementrian Pertanian. https://www.litbang.pertanian.go.id/a rtikel/?f_j=gedong+gincu\&f_m $=\& f_{-}$ $\mathrm{p}=$

Tjiptono, Fandy \& Gregotius Chandra. (2012). Pemasaran strategik. (2 Ed). ANDI: Yogyakarta. 